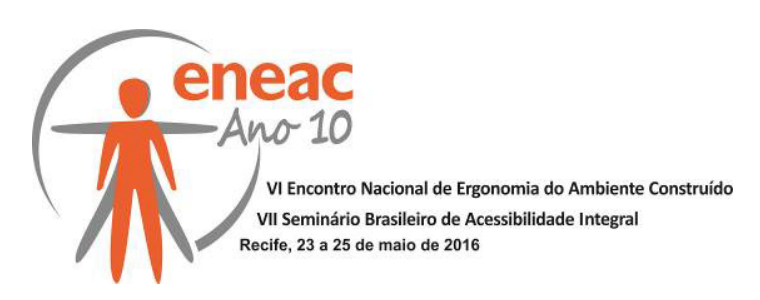

\title{
RELAÇÃO CLIENTE E AMBIENTE CONSTRUÍDO: ESTUDO DE CASO EM PANIFICADORA
}

\author{
SILVEIRA, Carolina Morgado de Freitas (1); \\ BINS ELY, Vera Helena Moro (2) \\ (1) Universidade Federal de Santa Catarina, Mestranda em Arquitetura e Urbanismo \\ e-mail: arq.carolinamorgado@gmail.com \\ (2) Universidade Federal de Santa Catarina, Doutora em Engenharia de Produção \\ e-mail: vera.binsely@gmail.com
}

\begin{abstract}
RESUMO
Diante da necessidade de adequação do ambiente construído aos usuários e às atividades desenvolvidas, este artigo apresenta um estudo de caráter investigativo e qualitativo em uma panificadora. Por meio de uma abordagem multimétodos, envolvendo pesquisa bibliográfica e documental, visitas exploratórias, mapa comportamental e entrevistas, buscou-se compreender como os clientes vivenciam e avaliam a atmosfera do estabelecimento comercial em análise. Os resultados permitiram desenvolver diretrizes e parâmetros projetuais, que visam reforçar os aspectos positivos encontrados e solucionar os negativos, contribuindo assim, para qualidade de futuros projetos.
\end{abstract}

Palavras chave: atmosfera; arquitetura comercial; avaliação pós-ocupação (APO) e ergonomia.

\begin{abstract}
According to the need to adapt the built environment to users and activities developed, this paper presents an investigative and qualitative study in a bakery. Through a multimethod approach involving bibliographical research and documental, exploratory visits, behavioral mapping and interviews, it sought to understand how the customers experience and evaluate the analyzed store atmosphere. The results allowed to develop guidelines and projective parameters, that aims to reinforce the positive aspects found and solve the negative, thus contributing to the quality of future design.
\end{abstract}

Keywords: atmosphere; commercial architecture; post-occupancy evaluation (POE) and Ergonomics.

\section{INTRODUÇÃO}

Cada vez mais presente no cotidiano das pessoas, as panificadoras são essencialmente estabelecimentos comerciais em que há a produção e venda de pães. Atualmente, além da primordial função relacionada à alimentação e consumo, permitem a seu público exercer diferentes atividades. Assim, é comum associar as panificadoras a um espaço multifuncional e de integração social, pois representa a possibilidade da leitura, entretenimento, encontro, conversa e confraternização.

Na presente sociedade, nota-se a busca por tornar a experiência da compra e do consumo confortável, agradável e de alto significado, pois, como aponta Underhill (2009) o marketing, a propaganda, as promoções não são mais suficientes para fidelizar o cliente. Ao valorizar a 


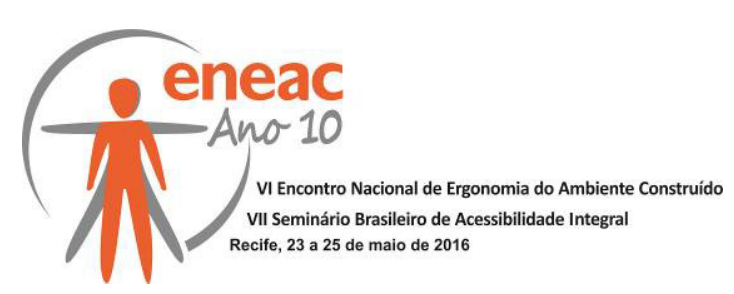

experiência do usuário, reconhece-se o papel central do ser humano. Nesta perspectiva se faz necessária uma visão holística com o aporte de diferentes áreas do conhecimento como arquitetura, design, marketing e psicologia ambiental.

Esta pesquisa foi desenvolvida na disciplina de Avaliação Ambiental em Função do Usuário, do programa de Pós-Graduação em Arquitetura e Urbanismo (PósARQ) da Universidade Federal de Santa Catarina (UFSC). A escolha do objeto de estudo atendeu critérios préestabelecidos como: caracterizar-se como um ponto de venda, pertencer a um negócio local, marca consolidada, área útil mínima de $20 \mathrm{~m}^{2}$ e com grande fluxo de pessoas.

Com o objetivo de avaliar o ambiente, por meio da observação do comportamento e compreensão da percepção de seus clientes, selecionou-se a primeira filial de uma reconhecida panificadora na cidade de Florianópolis. Pretende-se identificar os pontos positivos e negativos advindos da relação entre pessoa e o ambiente construído, a fim de elaborar diretrizes e parâmetros projetuais que colaborem para qualidade de espaços comerciais do setor alimentício.

\section{REFERENCIAL TEÓRICO}

Ao considerar a complexidade dos diferentes aspectos envolvidos na relação dinâmica entre ser humano e ambiente, verifica-se a importância de estudos transdisciplinares. Por essa razão, a segunda seção deste artigo destina-se a esclarecer conceitos tocantes a ergonomia, psicologia ambiental e atmosfera do ponto de venda.

Ao pressupor a adequação dos espaços às necessidades e anseios de seus usuários no desenvolvimento de suas atividades, a ergonomia estuda as interações entre as pessoas com a tecnologia, a organização e o ambiente. De enfoque abrangente, a linha de pesquisa da ergonomia ambiental, também chamada ergonomia do ambiente construído, examina a forma como as pessoas interagem com o ambiente, considerando aspectos sociais, psicológicos e organizacionais (VASCONCELOS; VILLAROUCO; SOARES, 2010).

Com enfoque também nos seres humanos, a psicologia ambiental investiga as relações entre comportamento e experiência, e o ambiente construído e natural, em seus contextos cotidianos e reais. Segundo Bell et al. (1978), o ambiente não define o comportamento das pessoas, porém, existe uma inter-relação em que um não pode ser compreendido separadamente do outro. Estuda, portanto, o comportamento, considerando o ambiente como parte integral desse processo.

A inter-relação entre indivíduo e ambiente também é explorada na área do marketing. Pioneiro na pesquisa das características espaciais que possam influenciar as atividades de comercialização, Kotler (1974, p.50), define a atmosfera do ponto de venda como "o planejamento consciente do espaço com o intuito de criar efeitos emocionais específicos em compradores". Tal conceito é aprofundado por Baker et al. (2002), que a compreende como uma estrutura intencional e controlada de estímulos do ambiente, que englobam a relação entre os fatores de projeto, fatores ambientais e fatores sociais.

Ao afirmar que no primeiro café de Damasco, o explorador francês Jean Chardin encontrou "o universo que girava em torno do ato de tomar um café", Pinheiro (2011, p. 125), chama a atenção para a valorização da experiência do usuário. A metáfora da percepção desta atmosfera extrapola o sabor oriundo da qualidade dos grãos em si, e engrandece a vivência social ou rituais individuais. Assim, este autor enfatiza que vivemos em uma era em que se faz necessário vivenciar, sentir e despertar sensações que levem ao destaque, ao encontrar lugar e relevância na vida das pessoas.

Nota-se, portanto, aproximação da alimentação com as interações sociais. Isto porque os alimentos não respondem apenas à necessidade de sobrevivência, mas encontram-se 


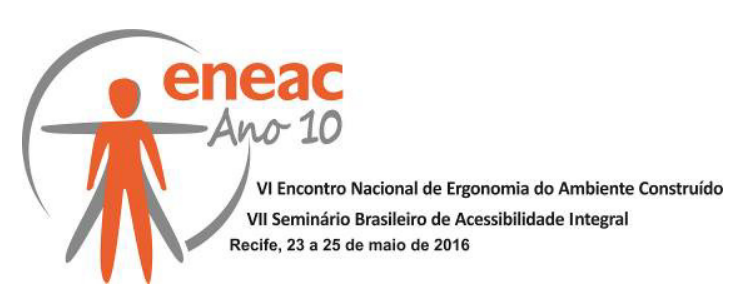

profundamente ligados ao prazer e ao exercício da sociabilidade (BOER, 2013). Para Moreira (2010), tais conexões são tão enraizadas que até hoje associamos comida e bebida às relações de boa convivência, ideia essa ligada a etimologia da palavra latina companion: pessoa com quem partilhamos o pão.

As relações entre as pessoas e os alimentos, por muitos séculos restritas aos limites domésticos, nas duas primeiras décadas do século XXI vem se modificando. Fruto do ritmo acelerado da vida contemporânea urbana, tal transformação trouxe novas possibilidades de interpretação do comer. A dificuldade de retornar para casa, devido a compromissos de trabalho e estudo, contribuiu para o grande número de ambientes comerciais voltados à alimentação rápida, como é caso das panificadoras, que se tornaram espaços flexíveis, práticos e acessíveis para as refeições (COLLAÇO, 2004).

\section{METODOLOGIA}

Nesta pesquisa de caráter exploratório, interdisciplinar e qualitativo adotou-se uma abordagem multimétodos, como: pesquisa bibliográfica e documental, visitas exploratórias, mapa comportamental e entrevistas.

Para a construção do aporte teórico que norteia este artigo, bem como a definição dos métodos a serem utilizados, foi essencial a pesquisa bibliográfica. Inicialmente, visando conhecer o cenário para a ação humana e sua dinâmica, foi realizada uma entrevista com um dos proprietários da panificadora, revelando a história e conceito da empresa, qualificando seu público alvo, rotinas e características do corpo laboral.

Em seguida, o contexto real do ambiente foi melhor conhecido, por meio da análise de documentos como o projeto arquitetônico e de interiores do estabelecimento, aliado às visitas exploratórias, que oportunizaram o levantamento dimensional e registros fotográficos.

Com o intuito de evidenciar os comportamentos e contatos sociais, aplicou-se o mapeamento comportamental, que permitiu identificar o perfil de seus usuários, suas atividades, possíveis zonas de ocupação e principais fluxos. Em complemento à observação, foram realizadas entrevistas semiestruturadas, que ao dar voz aos clientes, propiciou a compreensão da forma como estes avaliam os atributos que compõem a atmosfera da panificadora em estudo.

\section{RESULTADOS E DISCUSSÃO}

Os dados coletados visaram compreender como os clientes vivenciam e avaliam a atmosfera do estabelecimento comercial em análise. Os principais resultados obtidos são apresentados a seguir, organizados conforme quatro tópicos: 1) caracterização dos usuários; 2) caracterização do ambiente; 3) avaliação do ambiente em uso; e 4) percepção ambiental do usuário.

\subsection{Caracterização dos usuários}

Os usuários da panificadora podem ser classificados como clientes e funcionários. Este artigo centra-se nos usuários esporádicos, isto é, os clientes. Contudo, vale destacar que os aspectos relacionados aos usuários cotidianos - atendentes, em especial quanto à avaliação do trabalho sob o viés da psicologia ambiental e da ergonomia, foram abordados em um artigo específico (SILVEIRA; BINS ELY, 2015).

O público do estabelecimento comercial é bastante diversificado, englobando pessoas de ambos os gêneros, de diferentes idades e características físicas. A Tabela 01, disposta a seguir, sintetiza as características da amostra não probabilística de 49 pessoas. Pode-se 


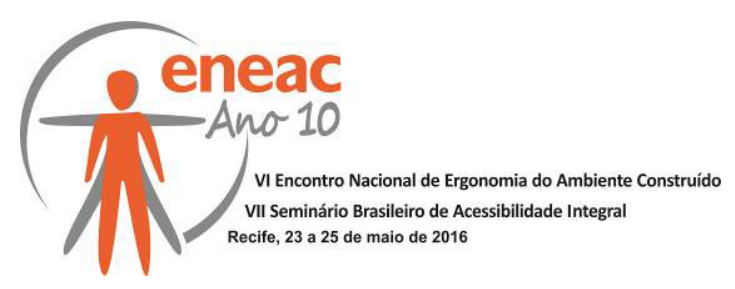

inferir que há um equilíbrio quanto ao gênero, porém nota-se o predomínio de pessoas cuja faixa etária varia entre 31 a 50 anos, e, destaca-se ainda, o grande número de pessoas acompanhadas de familiares.

Tabela 01 - Caracterização dos usuários da amostra.

\begin{tabular}{|c|c|c|c|c|c|c|c|}
\hline \multirow{2}{*}{\multicolumn{2}{|c|}{ Caracteristica }} & \multicolumn{5}{|c|}{ Quantidade de pessoas } & \multirow{3}{*}{$\begin{array}{l}\text { Percentua } \\
51,00 \%\end{array}$} \\
\hline & & \multicolumn{4}{|c|}{ Subtotal } & \multirow{2}{*}{$\begin{array}{l}\text { Total } \\
25\end{array}$} & \\
\hline & Feminino & 03 & 04 & 03 & 15 & & \\
\hline Gênero & Masculino & 07 & 04 & 04 & 09 & 24 & $49,00 \%$ \\
\hline \multirow{7}{*}{$\begin{array}{c}\text { Faixa Etária } \\
\text { (anos) }\end{array}$} & Inf. a20 & - & - & - & 07 & 07 & $14,30 \%$ \\
\hline & 21 a 30 & 01 & 02 & 03 & - & 06 & $12,20 \%$ \\
\hline & 31 a 40 & 01 & 02 & 03 & 12 & 18 & $36,70 \%$ \\
\hline & 41 a 50 & 02 & 02 & 01 & 04 & 09 & $18,50 \%$ \\
\hline & 51 a 60 & 05 & 02 & - & - & 07 & $14,30 \%$ \\
\hline & 61 a 70 & 01 & - & - & - & 01 & $02,00 \%$ \\
\hline & Sup. a 71 & - & - & - & 1 & 01 & $02,00 \%$ \\
\hline \multicolumn{2}{|c|}{ Quanto a companhia } & $\begin{array}{l}\text { Sozinho } \\
(20,40 \%)\end{array}$ & $\begin{array}{c}\text { Casal } \\
(16,35 \%)\end{array}$ & $\begin{array}{l}\text { Amigos } \\
(14,30 \%)\end{array}$ & $\begin{array}{l}\text { Família } \\
(48,95 \%)\end{array}$ & \multicolumn{2}{|c|}{$\begin{array}{c}\text { Total } 49 \text { pessoas } \\
(100 \%)\end{array}$} \\
\hline
\end{tabular}

Fonte: Pesquisadoras, 2016.

\subsection{Caracterização do ambiente}

Localizada em contexto urbano, próximo à uma importante rodovia, a panificadora avaliada está implantada dentro de um centro de jardinagem. Sua área útil total é de $175 \mathrm{~m}^{2}$, organizados em dois principais setores: operacional e comercial. Destinado para produção, administração, estoque, vestiários e banheiros, o setor operacional, é de acesso restrito aos colaboradores da panificadora. O setor comercial possui área útil de cerca de $100 \mathrm{~m}^{2}$. Destacado em vermelho, na Figura 01, abaixo, apresenta-se o objeto de estudo, escolhido por propiciar interações entre ambiente, clientes e atendentes.

Figura 01 - Caracterização do ambiente.

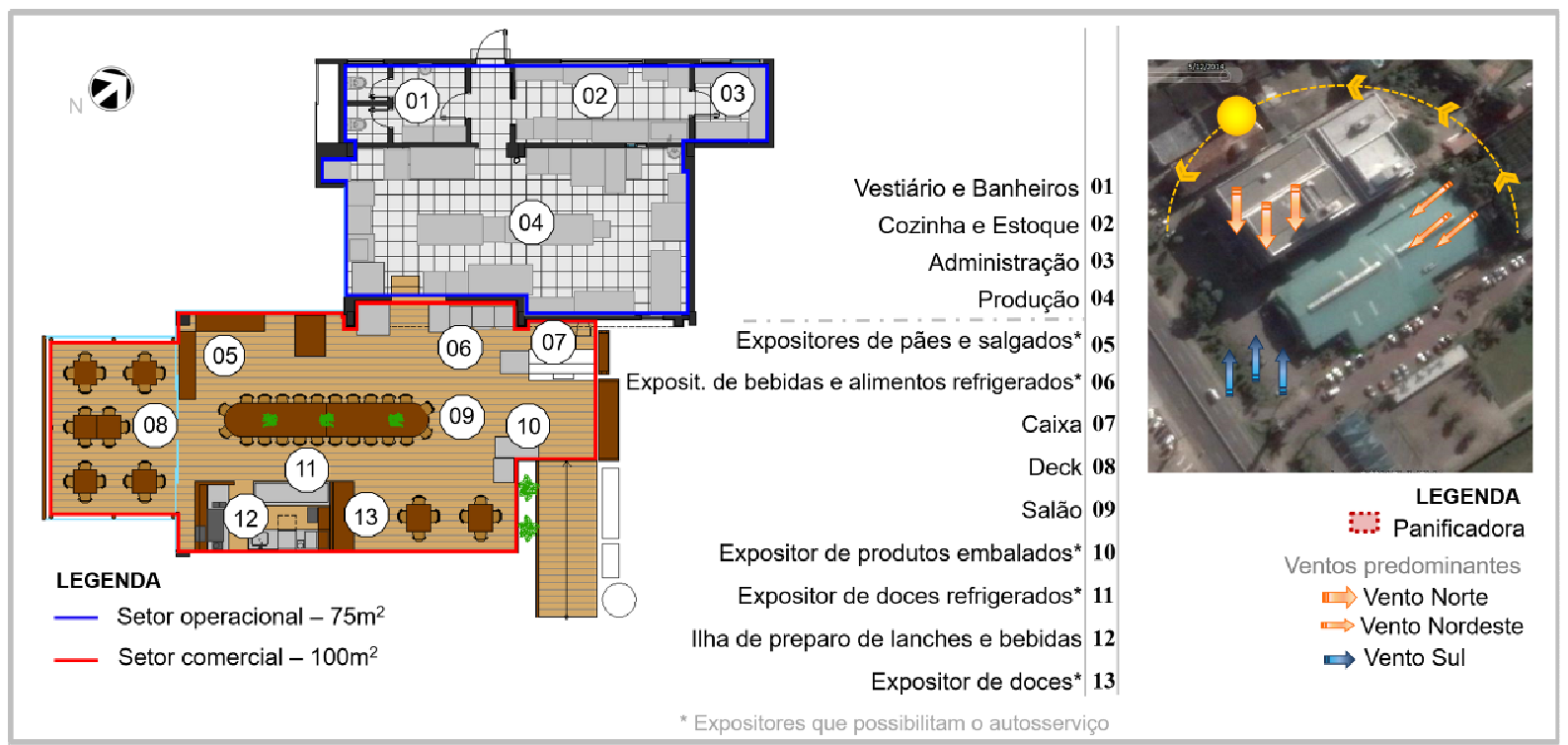

Fonte: Pesquisadoras, 2016. 


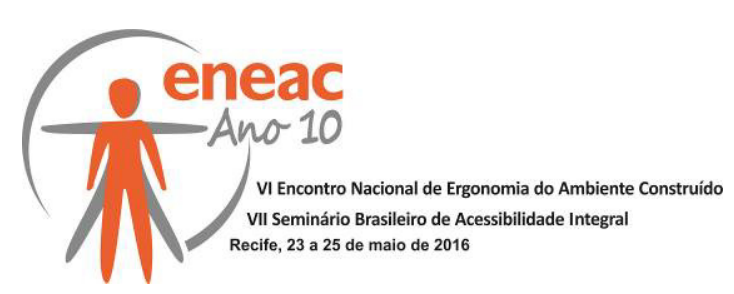

Como aponta a Figura 01, exposta na página anterior, $10 \mathrm{~m}^{2}$ destinam-se ao caixa (07) e ilha de preparo de lanches e bebidas (12), ambos de uso exclusivo dos funcionários. O salão de autoatendimento e consumação (09), com aproximadamente $90 \mathrm{~m}^{2}$, acomoda 56 pessoas sentadas, oferecendo aos clientes a possibilidade de ocuparem uma mesa privativa, seja ela dentro do salão ou no deck (08), ou, ainda, uma mesa coletiva. É relevante evidenciar que o banheiro para uso do público é o mesmo disponibilizado pelo centro de jardinagem, ou seja, fora do perímetro da panificadora.

A configuração espacial semiaberta é uma característica marcante. Embora interessante pela amplitude proporcionada e pelo contato visual com elementos naturais no entorno imediato, esta peculiaridade prejudica o controle de ruídos e também da temperatura. Vale ressaltar que o ambiente possui duas fachadas em vidro, com orientação oeste e noroeste respectivamente, o que favorece o aquecimento passivo. Esta situação é agravada pelo calor gerado pelo forno de pães dentro do salão, próximo a mesa coletiva.

A cobertura é inclinada, e seu fechamento ocorre por meio de telhas termoacústicas, popularmente conhecidas como telha sanduíche - telha superior, isolante, telha inferior. $O$ ambiente possui amplo pé-direito, com dimensão mínima de aproximadamente $5 \mathrm{~m}$ de altura.

Como ilustra a Figura 02, abaixo, a ambiência da panificadora é marcada pelas linhas projetuais retilíneas e pelo forte caráter rústico. A linearidade predominante no desenho do espaço é contraposta por formas sinuosas presentes na cúpula das luminárias pendentes, nas extremidades da mesa coletiva e nas cadeiras torneadas. Já os revestimentos como a madeira e o tijolo de barro, contrastam com elementos de translucidez como o vidro e elementos metálicos como o aço inoxidável. Na paleta de cores sobressaem-se as tonalidades neutras, como o marrom e o bege. Destaque para o colorido dos alimentos, somado àquele oriundo da diversidade de vegetações expostas no centro de jardinagem.

Figura 02 - Ambiência da panificadora analisada.

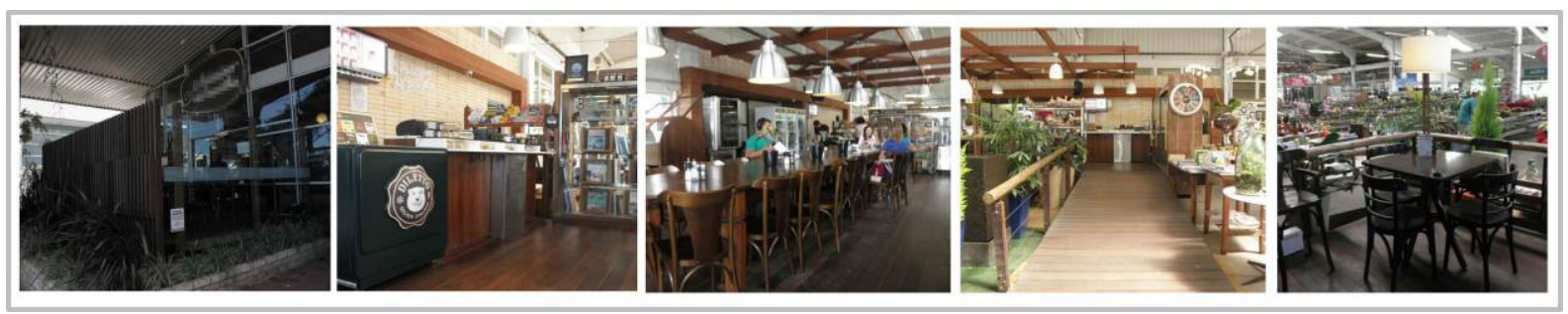

Fonte: Pesquisadoras, 2014.

\subsection{Avaliação do ambiente em uso}

Para Pinheiro (2011) talvez a maior lição seja a de aprender a acompanhar mais de perto o ponto de vista das pessoas que utilizam produtos e serviços. A observação direta das interações entre os ambientes e seus usuários, permite coletar dados, não verbalizáveis, que relacionam os elementos arquitetônicos com os aspectos sutis e simbólicos da relação do ser humano com o mundo. O mapeamento comportamental, por meio de uma observação sistemática, propicia a identificação do perfil dos usuários, comportamentos e contatos sociais. Além disso, permite representar graficamente suas atividades, possíveis zonas de ocupação e principais fluxos (RHEINGANTZ et al., 2009).

Realizado no dia 09 de dezembro de 2014, terça-feira, no período compreendido entre 11:00 e 19:00 horas, englobando os momentos de maior movimento no turno da tarde - 12:00 às 13:30 horas e 16:00 às 18:30 horas, a observação teve duração de 4 horas. Os dados foram sintetizados na Figura 03, a seguir, destacando-se os principais fluxos e setores ocupados. 


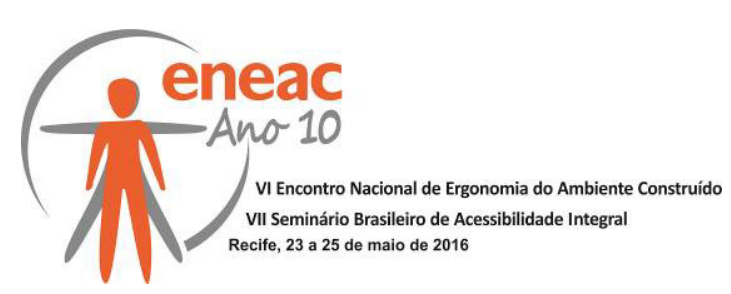

Figura 03 - Mapa de ocupação e setores relacionados.

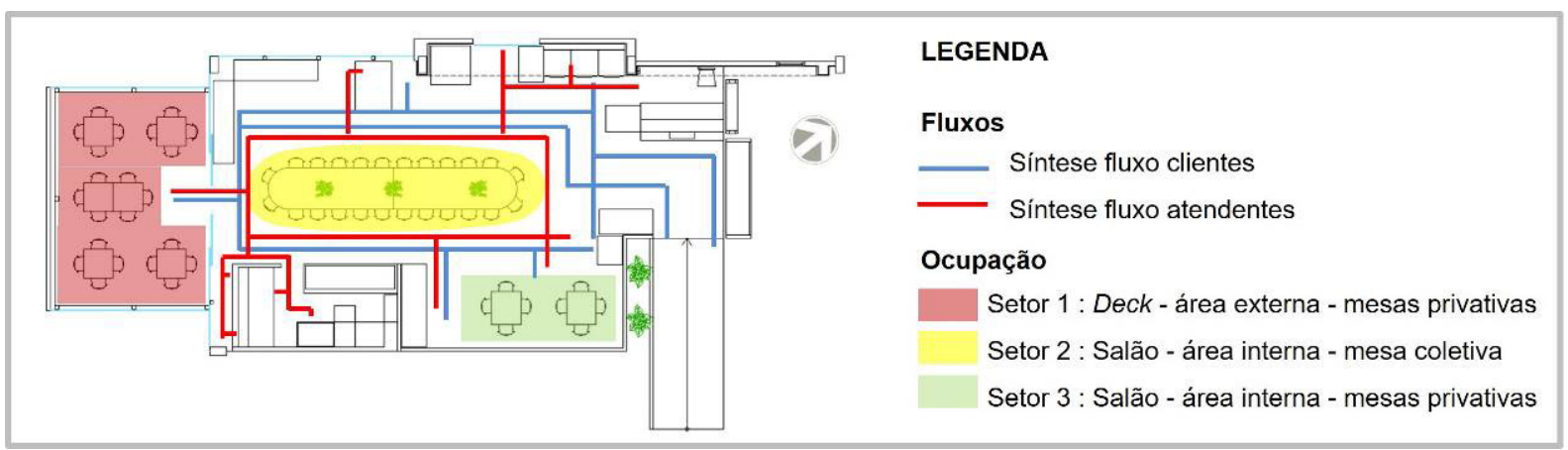

Fonte: Pesquisadoras, 2016.

Os dados referentes ao Setor 1 estão representados no Quadro 01, disposto na sequência. Com percentual de $26,55 \%$ de ocupação, este é o segundo setor na preferência dos clientes. Uma característica peculiar é sua localização em área externa semiaberta e coberta, o que significa dizer que sofre influência das condições climáticas.

O Setor 1 é ocupado, em maioria, pela faixa etária dos 31 aos 40 anos. No que diz respeito a gênero, há predomínio de mulheres. Quanto à companhia, constatou-se maior número de pessoas com elo familiar, seguido de amizade. Uma possível justificativa para esse fato seria a maior privacidade que a configuração espacial do deck proporciona. Assim, este setor pode ser interpretado como mais propício a pequenas reuniões, uma conversa mais íntima, bem como demonstrações de afeto. Ressalta-se ainda, que alguns indivíduos, em especial dentro do grupo dos casais, focados em sua relação amorosa, mantiveram conexão visual em seu companheiro (a), dificultando a aproximação das pesquisadoras. É importante mencionar que na referida área, constatou-se maior tempo de permanência dos consumidores, variando de 25 minutos a aproximadamente 4 horas.

\section{Quadro 01 - Caracterização ocupação Setor 1.}

\begin{tabular}{|c|c|c|c|c|c|c|c|c|c|c|c|c|}
\hline \multicolumn{11}{|c|}{ SETOR 1 ( $26,55 \%$ da amostra) } & \multicolumn{2}{|c|}{ Gênero } \\
\hline & & \multicolumn{8}{|c|}{ Número de pessoas por gênero } & \multirow{2}{*}{$\begin{array}{l}\text { Total de } \\
\text { pessoas }\end{array}$} & & \multirow{5}{*}{$\begin{array}{l}=\text { Feminino } \\
=\text { Masculino }\end{array}$} \\
\hline & & $\mathrm{F}$ & M & $\mathrm{F}$ & M & $\mathrm{F}$ & M & $\mathrm{F}$ & M & & $60 \%$ & \\
\hline \multirow{7}{*}{$\begin{array}{l}\text { Faixa } \\
\text { Etária } \\
\text { (anos) }\end{array}$} & Inf. a 20 & - & - & - & - & - & - & 2 & - & 2 & $40 \%$ & \\
\hline & 21 a 30 & - & - & - & - & 1 & - & - & - & 1 & $20 \%$ & \\
\hline & 31 a 40 & - & - & - & - & 1 & 2 & 2 & 1 & $\overline{6}$ & $0 \%$ & \\
\hline & 41 a 50 & & 1 & - & - & 1 & - & - & - & $\overline{2}$ & \multicolumn{2}{|c|}{ Quanto a companhia } \\
\hline & 51 a 60 & - & 1 & - & - & - & - & - & - & 1 & $50,00 \%$ & \\
\hline & 61 a 70 & - & - & - & - & - & - & - & - & - & $40,00 \%$ & = Sozinho \\
\hline & Sup. a 71 & - & - & - & - & -- & - & 1 & - & 1 & $30,00 \%$ & = Casal \\
\hline \multirow{2}{*}{ Subtotal } & & 0 & 2 & 0 & 0 & 3 & 2 & 5 & 1 & \multirow{2}{*}{13} & $20,00 \%$ & Amigos \\
\hline & & & & & & & & & & & $10,00 \%$ & \\
\hline \multicolumn{2}{|c|}{ Quanto a companhia } & \multicolumn{2}{|c|}{ Sozinho } & \multicolumn{2}{|c|}{ Casal } & \multicolumn{2}{|c|}{ Amigos } & \multicolumn{2}{|c|}{ Família } & & $0,00 \%$ & \\
\hline
\end{tabular}

Fonte: Pesquisadoras, 2016.

Mais utilizado pelos clientes, o segundo setor, é delimitado pela mesa coletiva. Neste, como explicitado no Quadro 02, a seguir, verificou-se público adulto em maioria de 31 a 50 anos, seguido de jovens entre 21 e 30 anos. Observa-se também a menor diferença entre população feminina e masculina. Assim, o Setor 2 é o mais democrático, tanto pelo equilíbrio dos gêneros, mas também por abrigar, famílias, casais, amigos e indivíduos 


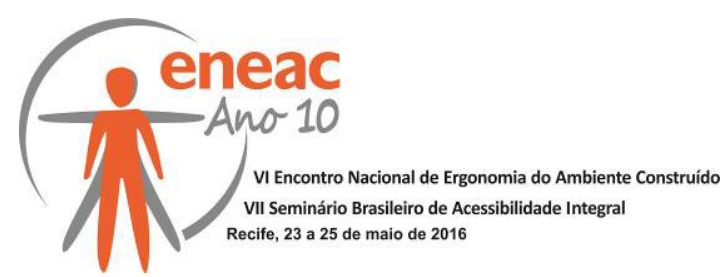

sozinhos. Salienta-se ainda que dentre os três setores, as pessoas sem companhia prévia, preferem este espaço, o que sugere que seja considerado agregador, no sentido de permitir conhecer pessoas ou simplesmente contar com companhia ao alimentar-se. O tempo de permanência, na mesa coletiva, oscilou entre 10 minutos a 2 horas. A média de 20 minutos está relacionada a curta duração das refeições.

\section{Quadro 02 - Caracterização ocupação Setor 2.}

\begin{tabular}{|c|c|c|c|c|c|c|c|c|c|c|c|c|}
\hline \multicolumn{11}{|c|}{ SETOR 2 (53,05\% da amostra) } & \multicolumn{2}{|c|}{ Gênero } \\
\hline & & \multicolumn{8}{|c|}{ Número de pessoas por gênero } & \multirow{2}{*}{$\begin{array}{l}\text { Total de } \\
\text { pessoas }\end{array}$} & $80,00 \%$ & \multirow{4}{*}{$\begin{array}{l}\text { = Feminino } \\
\text { = Masculino }\end{array}$} \\
\hline & & $\mathrm{F}$ & M & $\mathrm{F}$ & M & $\mathrm{F}$ & M & $\mathrm{F}$ & M & & $60,00 \%$ & \\
\hline \multirow{7}{*}{$\begin{array}{l}\text { Faixa } \\
\text { Etária } \\
\text { (anos) }\end{array}$} & Inf. a 20 & - & - & & & & & 2 & - & 2 & $40,00 \%$ & \\
\hline & 21 a 30 & 1 & - & 1 & 1 & 1 & 1 & - & - & 5 & \multirow{3}{*}{$\begin{array}{r}20,00 \% \\
0,00 \%\end{array}$} & \\
\hline & 31 a 40 & 1 & - & 1 & 1 & - & - & 2 & 2 & 7 & & \\
\hline & 41 a 50 & - & 1 & 1 & 1 & - & - & 1 & 3 & 7 & & \\
\hline & 51 a 60 & $\overline{1}$ & 3 & - & - & - & - & - & - & 4 & \multirow{3}{*}{$\begin{array}{l}50,00 \% \\
40,00 \% \\
30,00 \%\end{array}$} & \\
\hline & 61 a 70 & - & 1 & - & - & - & - & - & - & 1 & & = Sozinho \\
\hline & Sup. a 71 & - & - & - & - & - & - & - & - & - & & Casal \\
\hline \multirow{2}{*}{\multicolumn{2}{|c|}{ Subtotal }} & 3 & 5 & 3 & 3 & 1 & 1 & 5 & 5 & \multirow[b]{2}{*}{26} & $20,00 \%$ & $=$ Amigos \\
\hline & & & 3 & & & & & & & & $10,00 \%$ & \#amilia \\
\hline \multicolumn{2}{|c|}{ Quanto a companhia } & \multicolumn{2}{|c|}{ Sozinho } & \multicolumn{2}{|c|}{ Casal } & \multicolumn{2}{|c|}{ Amigos } & \multicolumn{2}{|c|}{ Família } & & $0,00 \%$ & \\
\hline
\end{tabular}

Fonte: Pesquisadoras, 2016.

O Quadro 03, abaixo, apresenta dados referentes à ocupação do setor 3. Espaço limite entre o objeto de estudo e o centro de jardinagem, neste setor encontram-se um alto número de crianças e adolescentes, superado apenas por indivíduos de 31 a 40 anos. Este contexto reflete, portanto, um perfil específico: casais e famílias. É comum encontrar usuários lendo, trabalhando em computador pessoal, ou, ainda, desenvolvendo tarefas escolares. Nesta perspectiva as mesas privativas, neste setor, transformam-se em uma extensão do espaço domiciliar, em cuja permanência, varia de 20 minutos a 2 horas

\section{Quadro 03 - Caracterização ocupação Setor 3.}

\begin{tabular}{|c|c|c|c|c|c|c|c|c|c|c|c|c|}
\hline \multicolumn{11}{|c|}{ SETOR $3(20,40 \%$ da amostra) } & \multicolumn{2}{|c|}{ Gênero } \\
\hline & & \multicolumn{8}{|c|}{ Número de pessoas por gênero } & \multirow{2}{*}{$\begin{array}{l}\text { Total de } \\
\text { pessoas }\end{array}$} & $80,00 \%$ & \multirow{5}{*}{$\begin{array}{l}\text { = Feminino } \\
=\text { Masculino }\end{array}$} \\
\hline & & $\mathrm{F}$ & $M$ & $\mathrm{~F}$ & M & $\mathrm{F}$ & M & $\mathrm{F}$ & M & & $60,00 \%$ & \\
\hline \multirow{7}{*}{$\begin{array}{l}\text { Faixa } \\
\text { Etária } \\
\text { (anos) }\end{array}$} & Inf. a 20 & - & - & - & - & - & - & - & 3 & 3 & $40,00 \%$ & \\
\hline & 21 a 30 & - & - & - & - & - & - & - & - & - & $20,00 \%$ & \\
\hline & 31 a 40 & - & - & - & - & - & - & 3 & 2 & 5 & $0,00 \%$ & \\
\hline & 41 a 50 & - & - & - & - & - & $\overline{-}$ & $\overline{-}$ & - & - & \multicolumn{2}{|c|}{ Quanto a companhia } \\
\hline & 51 a 60 & - & - & 1 & 1 & - & - & - & - & 2 & $100,00 \%$ & \multirow{6}{*}{$\begin{array}{l}\text { = Sozinho } \\
\text { = Casal } \\
\text { = Amigos } \\
\text { = Familia }\end{array}$} \\
\hline & 61 a 70 & - & - & - & - & - & - & - & - & - & $80,00 \%$ & \\
\hline & Sup. a 71 & - & - & - & - & - & - & - & - & - & $60,00 \%$ & \\
\hline \multirow{2}{*}{\multicolumn{2}{|c|}{ Subtotal }} & 0 & 0 & 1 & 1 & 0 & 0 & 3 & 5 & 10 & $40,00 \%$ & \\
\hline & & & 0 & & & & & & & & $20,00 \%$ & \\
\hline \multicolumn{2}{|c|}{ Quanto a companhia } & \multicolumn{2}{|c|}{ Sozinho } & \multicolumn{2}{|c|}{ Casal } & \multicolumn{2}{|c|}{ Amigos } & \multicolumn{2}{|c|}{ Familia } & & $0,00 \%$ & \\
\hline
\end{tabular}

Fonte: Pesquisadoras, 2016.

\subsection{Percepção ambiental do usuário}

Não se pode conceber o estudo do ambiente construído sem o entendimento da percepção do usuário. Isto porque sua análise extrapola as características físicas construtivas, envolvendo também o comportamento, impressões, sensações, necessidades e desejos 


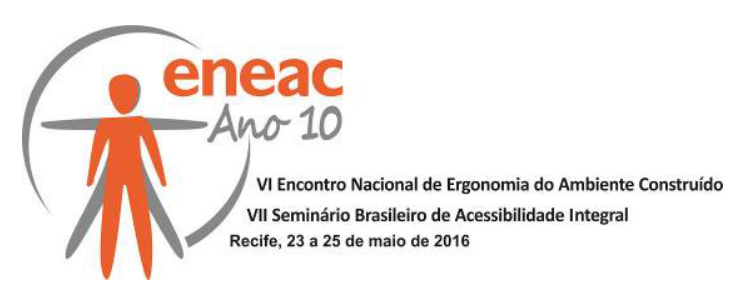

daqueles que vivenciam o espaço (VASCONCELOS; VILLAROUCO; SOARES, 2010). Para Bins Ely et al. (2006), é um desafio projetar para grandes massas, devido ao perfil anônimo dos usuários. Seguindo esta linha de raciocínio, na busca dos aspectos subjetivos da percepção da atmosfera do ponto de venda, foram realizadas entrevistas semiestruturadas. Estas abrangeram uma amostra não probabilística de 49 pessoas, cujo perfil foi previamente descrito na seção 4.1. As entrevistas tiveram três focos principais: 1) imagem real e 2) avaliação dos atributos da panificadora em estudo; e 3) imagem ideal de uma panificadora.

\subsubsection{Imagem real da panificadora em estudo}

Os elementos que mais agradam os clientes são: contato visual com a natureza - $31 \%$; seguido de ambiente aberto e ver o pão assando - 11,5\% cada; além do estilo e decoração, e mesa coletiva $-7,7 \%$ cada. As associações negativas, apontadas em maior número, configuram-se como: calor (especialmente no verão), e mesa coletiva - 11,50\% cada. Já o espaço apertado e o atendimento desagradam 7,7\% das pessoas, cada.

Vale destacar que $25 \%$ da amostra não destacou nenhum aspecto de descontentamento. 0 baixo índice de problemas citados pode ser interpretado como uma relação harmônica entre o ambiente e clientes. Isto porque há grande fidelização de clientes, uma vez que $49 \%$ da amostra frequenta a panificadora ao menos uma vez por mês; $46 \%$ uma vez por semana; e apenas $2 \%$ conheceu o ambiente no dia da entrevista.

\subsubsection{Avaliação dos atributos da ambiência}

Para a avaliação dos atributos da atmosfera foi utilizada a organização proposta por Baker et al. (2002), exposta no Quadro 4, disposto abaixo. Os fatores de projeto, são relativos a características visuais: funcionais - relacionada ao dimensionamento do mobiliário, distribuição do leiaute, fluxos e circulações - e estéticas - em alusão aos revestimentos e materiais e esquema cromático. Os fatores ambientais correspondem às sensações captadas pelos demais sentidos, como temperatura, iluminação, som e aromas. Os fatores sociais referem-se às relações interpessoais, como cortesia no atendimento, entre outros.

\section{Quadro 04 - Avaliação atributos ambiente conforme percepção dos clientes.}

\begin{tabular}{|c|c|c|c|}
\hline 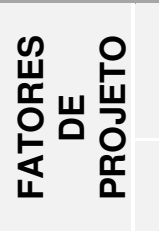 & \multirow{2}{*}{\multicolumn{3}{|c|}{$\begin{array}{l}\text { Dimensionamento do mobiliário } \\
\text { Distribuicão do leiaute }\end{array}$}} \\
\hline \multirow[t]{2}{*}{ Funcional } & & & \\
\hline & \multicolumn{3}{|l|}{ Fluxos e circulações } \\
\hline 䘮选 & \multicolumn{3}{|l|}{ Revestimentos, materiais e esquema cromático } \\
\hline Ш 口 & \multicolumn{3}{|l|}{ Contato visual com vegetação (entorno) } \\
\hline \multirow{4}{*}{$\begin{array}{l}\text { FATORES } \\
\text { AMBIENTAIS }\end{array}$} & Aroma/ cheiros & & \\
\hline & Som/ barulho & & \\
\hline & Temperatura & & \\
\hline & Iluminação & & \\
\hline \multirow{2}{*}{ FATORES SOCIAIS } & \multirow{2}{*}{\multicolumn{3}{|c|}{$\begin{array}{l}\text { Relacionamento com funcionários } \\
\text { Relacionamento com outros clientes }\end{array}$}} \\
\hline & & & \\
\hline LEGENDA & Excelente & Ruim & Péssimo \\
\hline
\end{tabular}

Fonte: Pesquisadoras, 2016.

Quanto aos fatores de projeto, destaca-se o contato visual com a vegetação, pois para maior parte dos entrevistados é interessante perceber a passagem do tempo e contemplar o movimento de pessoas e automóveis. A configuração espacial semiaberta foi associada a sensação de amplitude. Aos revestimentos, materiais e esquema cromático foi atribuído bom conceito, todavia foi sugerido "trazer o colorido das flores e plantas para dentro do 


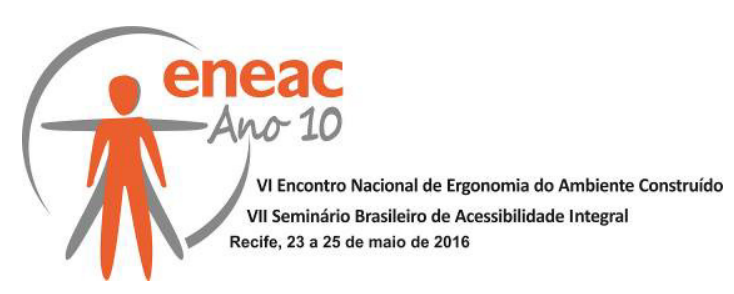

ambiente", já que para alguns clientes seria interessante "quebrar os tons de marrom". No tocante a categoria funcional, de forma geral o mobiliário e leiaute satisfaz os clientes. Porém o posicionamento dos pratos e talheres, acima de $1,50 \mathrm{~m}$, dificulta sua visualização e alcance. Houve, ainda, queixas quanto ao conflito de fluxos e sensação de aglomeração.

$O$ autoatendimento e o conceito direto do forno, na percepção dos clientes, são pontos fortes da panificadora. O forno dentro do salão cativa os entrevistados ao permitir "ver o pão assando", mas há reclamações relativas ao calor. Há ressalvas também quanto ao sistema de autoatendimento, devido a dois fatores: 1) carência de informações que esclareçam melhor seu funcionamento; 2) preferência pelo auxílio de um atendente, requisitada por parte das pessoas idosas, daquelas acompanhadas de crianças, e pessoas com deficiência.

$\mathrm{Na}$ categoria fatores ambientais, as melhores avaliações correspondem à iluminação e aroma. O cheiro de café e pão fresco, foi lembrado de forma expressiva, como um elemento convidativo e prazeroso. Já os ruídos provenientes da rua e das pessoas que se encontram no ambiente foram alvo de reclamações. O julgamento regular relativo a temperatura indica o desconforto causado pelo aquecimento passivo.

A mesa coletiva, apesar de seu caráter físico, associa-se também a um fator social, pois possibilita o convívio. Sua interpretação é variada e controversa. Grande parte dos entrevistados "adoram" seu caráter democrático e integrador. Porém alguns relatos indicam insatisfação, visto que "atrapalham a leitura ou conversa de assuntos pessoais". O descontentamento das pessoas de perfil mais reservado espelha-se em relatos de desistência ou de retornar em outro horário à panificadora, quando não havia assentos disponíveis junto às mesas privativas. Tais opiniões são inerentes à subjetividade humana, refletindo um importante aspecto da comensalidade, ou seja, a capacidade de compartilhar a mesa de refeições, associada à cultura e ao próprio estado emocional do indivíduo.

Ainda que haja más avaliações quanto à interação com outros clientes, o mesmo não ocorre na relação consumidor $x$ atendente, considerada excelente.

\subsubsection{Imagem ideal de uma panificadora}

Quando questionados sobre a panificadora ideal, as opiniões foram variadas. Os fatores relacionados a produtos e atendimento, como o pão fresco e o café quente foram mencionados em $26,95 \%$ das entrevistas, já 15,40\% não souberam responder.

Os demais $57,65 \%$, quanto aos atributos espaciais, citaram com maior frequência: 1) limpeza; 2) amplitude e boa ventilação; 3) boa distribuição e funcionalidade; 4) propiciar o convívio social e a leitura; 5 ) vitrine com produtos expostos, associados à ideia de "comer com os olhos"; 6) conforto do mobiliário como cadeiras e mesa; e 7) ambiente climatizado. Foram ainda sugeridos espaço para recados - interação do usuário com o ambiente; sofá; e música ao vivo/happy hour e banheiro família.

\section{DIAGNÓSTICO E RECOMENDAÇÕES}

A partir do diagnóstico proporcionado pela Avaliação Pós-Ocupação realizada, foi elaborada uma síntese apresentada a seguir no Quadro 05. Esta foi organizada de acordo com a percepção dos clientes sobre aspectos positivos e negativos da panificadora em análise. No referido quadro também estão expostas as recomendações que visam o conforto e qualidade ambiental, bem como orientações parâmetros projetuais para ambientes da mesma natureza. 


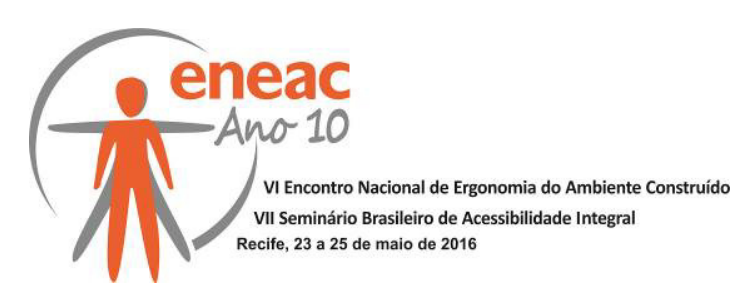

Quadro 05 - Percepção dos clientes (aspectos positivos e negativos) e recomendações.

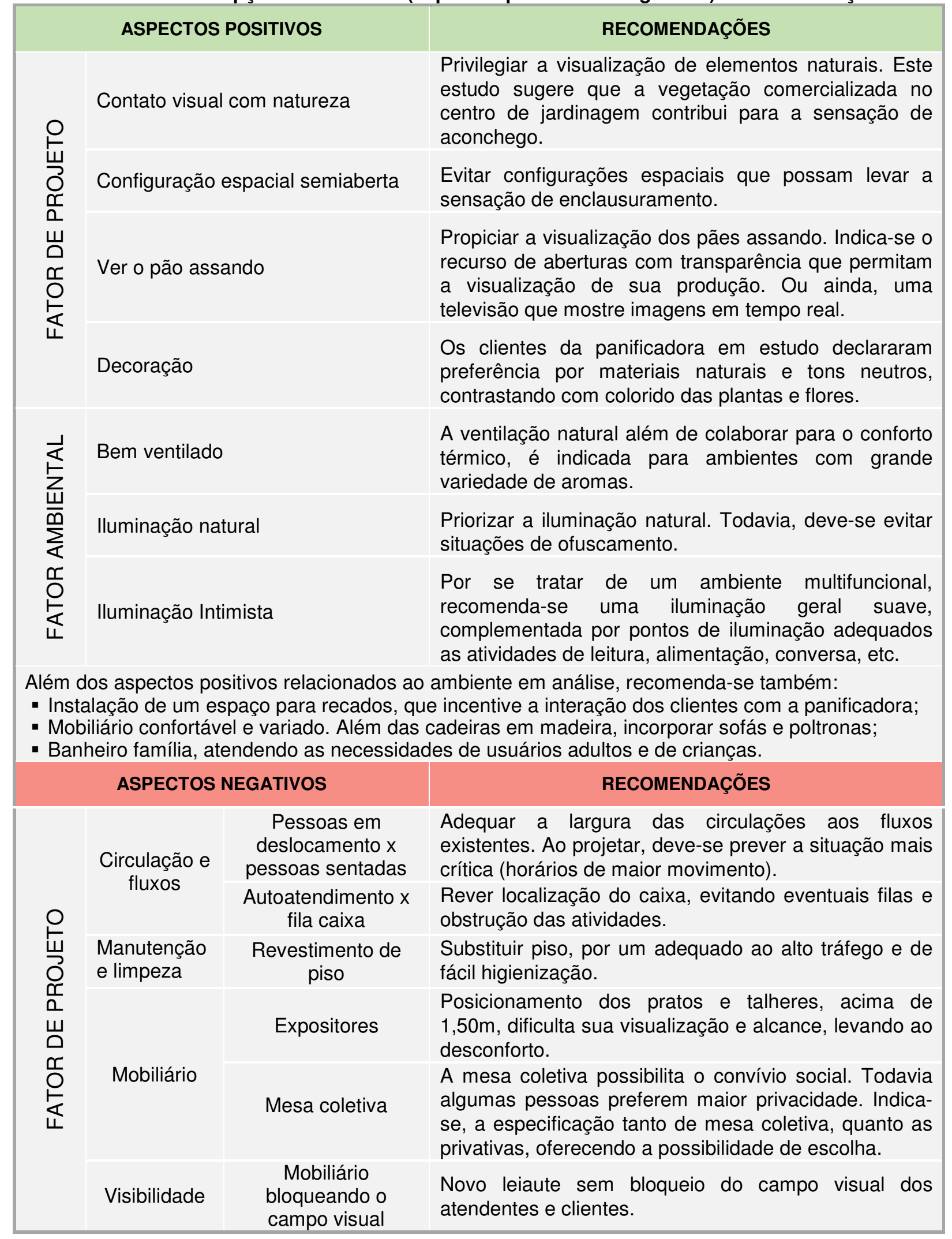




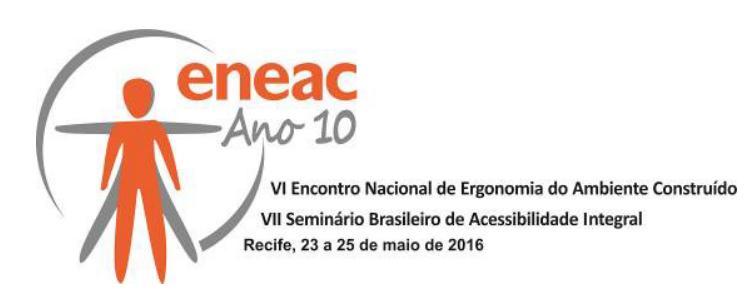

\begin{tabular}{|c|c|c|c|}
\hline 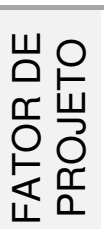 & Visibilidade & Autoatendimento & $\begin{array}{l}\text { Reposicionar o micro-ondas, pois os clientes pouco o } \\
\text { utilizam devido à sua baixa visibilidade. } \\
\text { Adicionar comunicação visual, em local privilegiado- } \\
\text { pontos em que o cliente toma suas decisões de } \\
\text { compra e consumo. }\end{array}$ \\
\hline \multirow{2}{*}{ 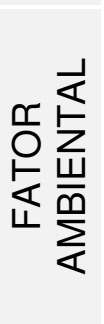 } & \multirow{2}{*}{$\begin{array}{l}\text { Conforto } \\
\text { ambiental }\end{array}$} & Sensação de calor & $\begin{array}{l}\text { Indica-se o uso de dispositivos de proteção solar na } \\
\text { face interna das fachadas envidraçadas. Além disso, } \\
\text { deve-se agir na segunda fonte de calor: o forno dentro } \\
\text { do salão, deslocando-o para a produção. }\end{array}$ \\
\hline & & Ruído excessivo & $\begin{array}{l}\text { Sugere-se o estudo de soluções para um ambiente de } \\
\text { configuração semiaberta, visando maior qualidade } \\
\text { acústica. }\end{array}$ \\
\hline
\end{tabular}

Fonte: Pesquisadoras, 2016.

\section{CONCLUSÃO}

A busca pela fidelização do cliente, nos dias atuais, aponta para a importância em tornar a experiência da compra e consumo confortável, agradável e de alto significado. Inúmeros fatores concorrem simultaneamente para propiciar qualidade nas interações entre os seres humanos e os ambientes comerciais.

Diante da diversidade humana e a variedade de suas atividades, para os arquitetos e designers, é um desafio projetar ambientes para diferentes usuários. A complexidade inerente a diversidade dos clientes é a razão pela qual este artigo focou-se em compreender como estes vivenciam e avaliam a atmosfera de uma panificadora.

Esta pesquisa teórico-prática utilizou multimétodos com aporte da ergonomia, psicologia ambiental e marketing. Os instrumentos utilizados se mostraram complementares e permitiram uma visão sistêmica. A pesquisa bibliográfica e documental, somada às visitas exploratórias, permitiram caracterizar a empresa, o ambiente, e, ainda, possibilitaram a aproximação com os usuários. O mapa comportamental identificou o perfil dos clientes e seu comportamento social. Este mapeamento revelou os principais atributos referentes a ocupação do ambiente e conflitos relacionados às atividades. Já as entrevistas evidenciaram a percepção dos clientes sobre a imagem real e ideal da panificadora e, ainda, sua avaliação a respeito da atmosfera do ponto de venda estudado.

O entrelaçamento das informações coletadas foi sintetizado e organizado em aspectos positivos e negativos. Pode-se afirmar que os pontos fortes da panificadora, são: contato com a natureza, configuração espacial semiaberta e a mesa comunitária. Todavia, como aspecto negativo destacou-se o conflito de fluxos. Além disso, observou-se que a altura elevada de alguns mobiliários dificulta a realização de atividades do autoatendimento, interferindo na autonomia e independência do cliente. Questões relacionadas ao conforto ambiental também merecem atenção, como: ruído excessivo e aquecimento passivo - em função da orientação do projeto arquitetônico e a incorporação do forno junto do salão.

Estes resultados subsidiaram o diagnóstico, gerando recomendações projetuais para o ambiente construído da panificadora em análise. Buscou-se reforçar os aspectos que agradam os clientes, e propôs-se também recomendações para solucionar os aspectos que carecem de melhorias ou devem ser evitados. Ao antecipar a identificações de possíveis conflitos contribui-se para outros projetos de natureza semelhante. 


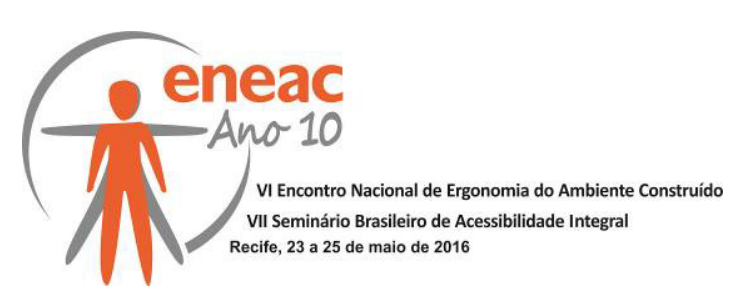

Nesta perspectiva, indica-se para futuras pesquisas, em espaços comerciais do setor alimentício, a análise integrada da percepção de seus usuários: clientes e atendentes. Isto, no intuito de bem atender as necessidades e anseios de variados públicos, desempenhando diversas funções, todas no mesmo local, em perfeita harmonia.

\section{REFERÊNCIAS BIBLIOGRÁFICAS}

BAKER, Julie et al. The influence of multiple store environment cues on perceived merchandise value and patronage intentions. Journal of Marketing. v. 66. p. 120-141, 2002.

BELL, Paul A. et al. Environmental Psychology: W.B Sauders Company, 1978.

BINS ELY, Vera H. M. et al. Percepção ambiental e avaliação técnico-funcional em Unidade de Internação Hospitalar. In: Anais XI Encontro Nacional de Tecnologia do Ambiente Construído, 2006, Florianópolis.

BOER, Luciema. Hospitalidade no restaurante Madalosso: comensalidade e sociabilidade. In: Anais Congresso Internacional de Gastronomia: Mesa Tendências SENAC, 2013, São Paulo.

COLLAÇO, Janine H. L. Restaurantes de comida rápida, os fast-foods, em praças de alimentação de shopping centers: transformações no comer. Revista Estudos Históricos, Rio de Janeiro, n. 33, 2004, p. 116-135.

KOTLER, Philip; MARTIN, Harold T. Atmospherics as a Marketing Tool. Journal of Retailing, vol.49, n. 4, p. 48-64, 1974.

MOREIRA, Sueli A. Alimentação e comensalidade: aspectos históricos e antropológicos. Revista Ciência e Cultura, São Paulo, volume 62, 2010.

PINHEIRO, Tennyson. Design Thinking Brasil: empatia, colaboração e experimentação para pessoas, negócios e sociedade. Rio de Janeiro: Elsevier, 2011.

RHEINGANTZ; Paulo A. et al. Observando a qualidade do lugar: procedimentos para avaliação pós-ocupação. Rio de Janeiros: Universidade Federal do Rio de Janeiro, Faculdade de Arquitetura e Urbanismo, Pós-Graduação em Arquitetura, 2009.

SILVEIRA, Carolina M. F.; BINS ELY, Vera H. M. Avaliação do trabalho dos atendentes em panificadora sob o viés da psicologia ambiental e da ergonomia. In: Anais XIII Encontro Nacional e IX Encontro Latino-Americano de Conforto no Ambiente Construído, 2015, Campinas-SP.

UNDERHILL, Paco. Vamos às Compras!: a ciência do consumo nos mercados globais. Tradução: Ricardo B. Vieira. Rio de Janeiro: Elsevier, Nova Ed. Ver. e atualizada, 6ㅉimpressão, 2009.

VASCONCELOS, Christianne; VILLAROUCO, Vilma; SOARES,Marcelo. Contribuição da psicologia ambiental na análise ergonômica do ambiente construído. Ação Ergonômica, v. 5, p. 14-20, 2010. 